\title{
Knowledge and Practice Regarding Colostrums Feeding to Newborn among Reproductive Age Group (15-49) Years Women
}

\author{
Manoj Prasad Kushwaha ${ }^{1}$, Bindu G. C. ${ }^{2}$, Binisha Sinha ${ }^{3}$ \\ ${ }^{1}$ Pediatrician, Department of Pediatrics, Lumbini Zonal Hospital, Butwal, Rupandehi, Nepal. Email: kushwahamanoj6399[at]gamil.com. \\ ${ }^{2}$ Undergraduate Student, Department of Nursing, Sanjeevani College of Medical Sciences, Affiliated to Purwanchal University, Butwal, \\ Rupandehi, Nepal. \\ ${ }^{3}$ Lecturer, Department of Nursing, Sanjeevani College of Medical Sciences, Affiliated to Purwanchal University, Butwal, Rupandehi, \\ Nepal.Email: me_binisha[at]yahoo.com
}

\begin{abstract}
Background \& Objective: Breastfeeding and colostrum remains the best food for the baby from the time immemorial. Thus, this study aims to assess the knowledge and practice regarding colostrum feeding among reproductive age group women. Materials \& Method: A descriptive cross-sectional study with 157 reproductive age group women was carried out in Ward No 2 of Tilottama Municipality. Consecutive Sampling Technique using pre-tested self-prepared interview schedule was used for the data collection. Collected data were analyzed using descriptive and inferential statistics. Results: The study revealed that about $45 \%$ of the respondents belong to age group (26-35) years. Majority (90.4\%) of the respondents were following Hindu religion. About $41 \%$ of the respondents were Brahmins. Nearly $71 \%$ of the respondents were house-makers and $75 \%$ were living in joint family. Majority (91\%) was literate and more than half of the respondents had 2 children. About $77 \%$ of the children were born at hospital and about $75 \%$ of the respondents had spontaneous vaginal delivery. The main sources of information about colostrum feeding were media, relatives, institutional delivery and friend. Nearly $87 \%$ of the respondents fed colostrum to their baby. The knowledge and practice regarding colostrum feeding was found to be better among mothers whose mode of delivery was spontaneous vaginal delivery and place of delivery was institution. Conclusion: The study concluded that the respondent had the adequate knowledge and practice regarding colostrum feeding. There are the different factors responsible for colostrum feeding practices like educating women and making them aware about the importance of colostrum feeding, family encouragement, health assistance, and awareness from different medias.
\end{abstract}

Keywords: Knowledge; practice; colostrum feeding

\section{Introduction}

It is well known fact that colostrum is important for promoting health, growth and development of the newborn, and it also helps to prevent against the infections. ${ }^{1}$ Breast feeding is a common practice in Nepal but the importance of colostrum feeding is still poorly understood due to cultural variations even in urban areas. Exclusive breast-feeding from birth to 6 months of age has prolonged health benefits and emotional bonding for mother and child and is associated with lower infant morbidity and mortality rate, and better growth \& development of the baby. ${ }^{2}$

Colostrum is the first milk produced by the mammary glands of mammals in late pregnancy just prior to giving birth and continuing through the early days of breastfeeding. ${ }^{3}$ Colostrum is very rich in proteins, carbohydrates, vitamin A, and sodium chloride, but contains lower amounts of lipids and potassium than normal milk. ${ }^{4-5}$ It also encourages the passage of stool. This helps to clear excess bilirubin which is produced in large quantities at birth and helps prevent jaundice. It contains various immunoglobulins like $\operatorname{IgA}$ (reactive to Escherichia coli virulence associated proteins) ${ }^{6}, \quad \operatorname{IgG}$ and $\operatorname{IgM}^{7}$.Other immune components of colostrum are lactoferrin, lysozyme, lactoperoxidase, complement and protein rich peptide (PRP). It also contains various cytokines and growth factors. PRP helps to fight against various viral infections like herpes viruses and HIV, bacterial and viral infections which are difficult to treat, various cancer, asthma, allergies and autoimmune diseases. It helps to reduce one of the leading causes of death like diarrhoea and Acute Respiratory Tract Infections. ${ }^{8}$

Colostrum contains high amounts of sodium, potassium, chloride, and cholesterol. This combination is believed to encourage optimal development of the infant's heart, brain, and central nervous system. This may account for the prolonged secretion of colostrum in mothers who deliver their babies prematurely. All these components offer premature infants the best chance for the optimal development of their fragile organs. ${ }^{9}$ Unfortunately, colostrum feeding is not given to newborn for various societal myths and misconception. In a false belief of gutty honey, sugar water, glucose, and mishri water were fed as pre-lacteal feeds. ${ }^{10}$

These values and beliefs regarding colostrum feeding affect directly and indirectly health of newborn infants and cause malnutrition and high mortality rate in infants. Thus, this cross sectional study was undertaken to assess the knowledge and practice regarding colostrum feeding among reproductive age group (15-49) years women in Tilottama Municipality, Butwal, Rupandehi, Nepal. The findings of this study would help mothers and nursing students in creating awareness program regarding importance of colostrum feeding to the newborns. 


\section{International Journal of Science and Research (IJSR)}

\section{Objectives}

- To assess the knowledge and practice regarding colostrum feeding.

- To find out the association between selected sociodemographic variables (Type of family, mother's education, religion, mode of delivery and place of delivery) and colostrum feeding practice.

\section{Materials and Methods}

Design: A cross-sectional descriptive study design. Setting: Ward No. 2 of Tilottama Municipality, Butwal, Rupandehi, Nepal. Sample Size: Sample size was calculated taking prevalence of colostrum feeding to be $39 \%$ as per study conducted by Rifat A et al. ${ }^{1} \& 15 \%$ allowable error. Using the formula $\mathrm{n}=4 \mathrm{pq} / \mathrm{L}^{2}$, the calculated sample size was 157. Sampling Technique: Consecutive Sampling Technique. Research Instrument: A self-prepared, pretested semi-structured interview schedule was used. Data Collection Procedure: Data was collected after obtaining permission from all the concerned authority of Tilottama Municipality. Consent was obtained from each respondent. The data collection period was 2 weeks in September 2017.Data Analysis Procedure: Collected data were analyzed using descriptive statistics (Mean, Median, Standard Deviation) and inferential statistics (Chi-Square Test) in SPSS version 16. P-value was calculated at $95 \%$ CI \& 5\% permissible error. Tests of Normality were used to check the distribution of data. Regarding scoring of practice, lower limit and upper limit was calculated at $95 \%$ CI \& 5\% permissible error and practice was categorized as poor and good regarding colostrum feeding. In checklist scoring was calculated as "Yes=2" \& "No=1" \& in Likert scale scoring was calculated as "Strongly Agree=5", "Agree=4", "Neutral=3", "Disagree=2" \& "Strongly Disagree $=1$ ". Checklist and 5-point Likert scale was used for assessment of practice related colostrum feeding.

\section{Results \& Findings}

The findings of the study showed that the mean age of the respondents were 32.13 years \& about $45 \%$ of respondents belonged to age group (26-35) years. Majority (90\%) of the respondents were following Hindu religion. Most of the respondents $(91.7 \%)$ were literate. About $71 \%$ of respondents were house-maker whileabout $24 \%$ were living in a joint family. The mean number of baby in the family was $2 \&$ man age of the child being 7.92 years. The mean duration of birth spacing was found to be 2.36 years Majority of the respondents had Institutional delivery $(77.7 \%) \&$ Spontaneous Vaginal Delivery (75.2\%).

About $86 \%$ of the respondents had some knowledge regarding colostrum feeding. More than half $(60 \%)$ of the respondents said that colostrum is a nutritious milk secreted after giving birth. About $79 \%$ said that colostrum is yellow \& sticky \& $62 \%$ said that it provided immunity to the newborn babies. More than three half $(81 \%)$ said that nothing should be fed to the baby besides breast-milk after birth of the baby. Nearly half $(56 \%)$ of the respondents said that colostrum should be fed immediately after birth. About $71 \%$ of the respondents said that colostrum feeding protects from respiratory tract infections and $52 \%$ respondents said that it protects mother from breast engorgement. Nearly $62 \%$ of the respondents had knowledge about colostrum through media. Only $7 \%$ of the respondents had practiced pre-lacteal feeding.

About $73.9 \%$ of the respondents had good practice regarding colostrum feeding through checklist analysis. Regarding analysis of 5-point Likert scale, study concluded that more than half $(64.3 \%)$ of the respondents had good practice regarding colostrum feeding and more than one third $(35.7 \%)$ had poor practice. Regarding overall practice score of checklist and Likert scale scoring, only more than half $(58 \%)$ of the respondents had good practice regarding colostrum feeding.

Regarding association of selected socio-demographic variables and colostrum feeding practice, practice of colostrum feeding was not statistically significant with religion $\quad(p-$ value $=0.217)$, educational status $(p-$ value $=0.239) \&$ type of family $(p$-value $=0.602)$, but statistically significant with mode of delivery (pvalue $=0.017) \&$ place of delivery $(p$-value $=0.000)$.

Table 1: Association between Place of Delivery \& Colostrum Feeding Practice ( $\mathrm{N}=157)$

\begin{tabular}{|c|c|c|c|}
\hline \multirow{2}{*}{ Place of Delivery* } & \multicolumn{2}{|c|}{$\begin{array}{c}\text { Colostrum Feeding } \\
\text { Practice }\end{array}$} & \multirow{2}{*}{ p-value } \\
\cline { 2 - 3 } & Poor & Good & \\
\hline $\begin{array}{c}\text { Institutional } \\
\text { Delivery }\end{array}$ & $34(21.66 \%)$ & $88(56.05 \%)$ & \multirow{2}{*}{$\mathbf{0 . 0 0 0}$} \\
\hline Home Delivery & $32(20.38 \%)$ & $3(1.91 \%)$ & \\
\hline
\end{tabular}

Key: * Fischer's Exact Test

Table 2: Association between Mode of Delivery \& Colostrum Feeding Practice $(\mathrm{N}=157)$

\begin{tabular}{|c|c|c|c|}
\hline \multirow{2}{*}{ Mode of Delivery** } & \multicolumn{2}{|c|}{$\begin{array}{c}\text { Colostrum Feeding } \\
\text { Practice }\end{array}$} & \multirow{2}{*}{ p-value } \\
\cline { 2 - 3 } & Poor & Good & \\
\hline $\begin{array}{c}\text { Spontaneous } \\
\text { Vaginal Delivery }\end{array}$ & $56(35.67 \%)$ & $62(39.49 \%)$ & \multirow{2}{*}{$\mathbf{0 . 0 1 7}$} \\
\hline Caesarean Section & $10(6.37 \%)$ & $29(18.47 \%)$ & \\
\hline
\end{tabular}

Key: ** Chi-Square Test

The study findings illustrated that the mothers who had institutional delivery had good colostrum feeding practice and also mothers who had spontaneous vaginal delivery had good colostrum feeding practice. It also depicted that mothers who had institutional spontaneous vaginal delivery had good colostrum feeding practice in Ward No.2 of Tilottama Municipality.

\section{Discussion}

This is a descriptive study, which was intended to assess the knowledge and practice regarding colostrum feeding among reproductive age group (15-49) years women. A total of 157 women were included in the study.

The study revealed that the majority of the reproductive age women $(86.6 \%)$ had some knowledge about colostrum feeding which is supported by the findings of the study 


\section{International Journal of Science and Research (IJSR) \\ ISSN (Online): 2319-7064}

Index Copernicus Value (2016): 79.57 | Impact Factor (2015): 6.391

conducted by Dr. Sunil Kumar Joshi ${ }^{11}$, where $74 \%$ of the women had heard about colostrum. Most of the women $(60.5 \%)$, knew the fact that colostrum is the nutritious milk secreted after giving birth, which is similar to the findings of the study ${ }^{11}$ where $69 \%$ knew that it is nutritious milk to be fed to the new born babies.

The findings of the study that about $56 \%$ of the respondent fed their babies with colostrum milk immediately after birth is similar to the findings of the study done by Sowmini Pet $\mathrm{al}^{12}$ in India that most of the mothers $(61 \%)$ started breastfeeding within 1 hour of delivery. The findings of the study done by Rifatet al. ${ }^{1}$ is also consistent with the findings of the present study that media being the major source of information regarding colostrum feeding to the newborns.

About $86 \%$ of the respondents said that colostrum milk benefits the baby. This findings is also consistent with the findings of the study done by Dr. Sunil Kumar Joshi ${ }^{11}$ where $69 \%$ of respondent supported the statement. According to one study in Southern Zambia conducted by FjeldE, ${ }^{13}$ among the urban mothers, colostrum was generally perceived as good, protective for the child and nutritious which is similar to the findings of the present study.

Many mothers lack knowledge about the importance of early initiation of breastfeeding and are not aware about the advantages of colostrum feeding. Some feel that colostrum looks bad. They even discard it on the advice of mothers-in-law. There is also misinterpretation that breast milk doesn't come in the first few days. Some mothers feel that it is insufficient for the baby's needs and water is necessary. ${ }^{11}$

Regarding association between selected sociodemographic variables and colostrum feeding practice, in a study conducted in Nigeria, feeding or discarding colostrum was significantly associated with health facility delivery ( $\mathrm{p}$-value $=0.003$ ) which is similar to the findings of the present study where place of delivery is statistically significant with colostrum feeding practice. ${ }^{14}$

The findings of the study conducted by Khan MA illustrated that $73 \%$ of the mothers gave colostrum to the child and family type \& mode of delivery was significantly associated with initiation of breastfeeding ( $p$-value $<0.001)$ whereas in the present study, mode of delivery was statistically significant with colostrum feeding practice (pvalue<0.05). ${ }^{15}$

A study conducted by Kamath S.P ${ }^{16}$ in India found that there was a statistically significant association between the mode of delivery and initiation of breastfeeding ( $p$ value $<0.05$ ) unlike the findings of the present study where mode of delivery was statistically significant with colostrum feeding practice ( $\mathrm{p}$-value $<0.05$ ).

\section{Conclusion}

The study concluded that majority of the respondents had some knowledge regarding colostrum feeding. The study findings also illustrated that the mothers who had institutional delivery had good colostrum feeding practice and mothers who had spontaneous vaginal delivery had also good colostrum feeding practice. It also depicted that mothers who had institutional spontaneous vaginal delivery had good colostrum feeding practice in Ward No.2 of Tilottama Municipality. Thus, institutional delivery should be promoted at all levels and it is being practiced as well in Nepal as Safe Motherhood Program. Though there are certain constraints as political instability, geographical variations, lack of physical infrastructure in hospitals, but still through community participation and governmental \& non-governmental support institutional delivery should be strengthened.

\section{Limitations of the Study}

The size of our sample was small and conducted in Tilottama Municipality only, sowe cannot generalize the results among all other Municipalities in Nepal. This study was a cross-sectional study and so, longitudinal studies would be better for identifying the impact of colostrum milk on newborns on their growth and development in Rupandehi district.

\section{Competing Interests}

The authors declare that they have no competing interests.

\section{Acknowledgements}

The authors wish to thank all the mothers of Ward No. 2, Tilottama Municipality, who participated in the study, Ms. Bindu G.C \& all the other members who directly or indirectly devoted their time making this study a success.

\section{References}

[1] Rifat A,Fakhar B, Saema S. Knowledge, Attitude and Practices about Colostrum Feeding among Pregnant Women in Military Hospital Rawalpindi of Pakistan. Open Journal of Nursing, Apr. 2016;6:309-313.

[2] Mannel R, Martens P, Walker M. Core Curriculum for Lactation Consultant Practice. 2nd ed, Jones and Bartlett Publishers, Sudbury, MA. May 2007:224, 304.

[3] LaLeche League International. What Is Colostrum? How Does It Benefit My Baby?http://www.1lli.org/faq/colostrum.html

[4] GhaiO.P, Paul V.K, Bagga A. Textbook of Paediatrics. 7th ed, CBS Publishers and Distributors, New Delhi, 2009:768.

[5] Science Daily (Homepage on the Internet). Colostrum.

http://www.sciencedaily.com/articles/c/colostrum.ht $\mathrm{ml}$.

[6] Loureiro I, Frankel G, Adu-Bobie J, Dougan G, Trabulsi L.R, Carneiro-Sampaio Magda M.S. Human Colostrum Contains IgA Antibodies Reactive to Enteropathogenic Escherichia coli Virulence-Associated Proteins: Intimin, BfpA,

\section{Volume 6 Issue 12, December 2017}




\section{International Journal of Science and Research (IJSR) \\ ISSN (Online): 2319-7064 \\ Index Copernicus Value (2016): 79.57 | Impact Factor (2015): 6.391}

EspA, and EspB. J. Pediatr. Gastroenterol. Nutr.Aug 1998;27(2):166-171.

[7] Arifeen S, Black R.E, Antelman G, Baqui A, Caulfield L, Becker S. Exclusive Breastfeeding Reduces Acute Respiratory Infection and Diarrhoea Deaths among Infants in Dhaka Slums. American Academy of Pediatrics. Oct. 2001;108(4):1-8 .

[8] Oddy W.H. The Impact of Breast Milk on Infant and Child Health. Breastfeeding Review.Nov 2002;10(3):5-18.

[9] United Nations Children's Fund. The State of the World's Children 2013: Children with Disabilities. Three United Nations Plaza, New York.

[10] UNICEF.2009.The Baby Friendly Hospital Initiative.

http://www.unicef.org/newsline/tenstps.htm.

[11] Joshi S, Barakoti B, Lamsal S. Colostrum Feeding: Knowledge, Attitude and Practice in Pregnant Women in a Teaching Hospital in Nepal. WebmedCentral Medical Education. Aug 2012;3(8):1-20.WMC003801.

[12] Somane S. A descriptive study to Assess the Knowledge and Attitude of Third Trimester Antenatal Mothers regarding Colostrum Feeding. Asian JNur.Edu and Research. Aug 2016;6(3):292300 .

[13] Fjeld E, Siziya S, Katepa-Bwalya M, Kankasa C, Moland K.M, Tylleskär T. 'No sister, the breast alone is not enough for my baby' a qualitative assessment of potentials and barriers in the promotion of exclusive breastfeeding in southern Zambia. International Breastfeeding Journal. Nov 2008;3:26.

[14] Nnebue C.C, Duru C.B, Uwakwe K.A, Ifeadike C.O, Anyanwu B.C, Adinnu K.M, Nwaneri P.O, Ufoh I.J. Neonatal care - what do mothers in a rural Nigerian community know and practice? J. Neonatal Perinatal Med. Sep 2016;9(3):303-312.

[15] Khan M.A, Qureshi Z, Khan K.A, Gill F.N. Patterns and Determinants of Breastfeeding Among Mothers Infants Pairs in Dera Ghazi Khan, Pakistan. J.Ayub Med Coll Abbottabad. Oct-Dec 2016;28(4):750754.

[16] S.P Kamath, D Garg,M.K Khan, AJain, B.S Baliqa. Perceptions and practices regarding Breastfeeding among Postnatal Women at a District Tertiary Referral Government Hospital in Southern India. Scientifica (Cairo). 2016:5430164. Epub 2016 Oct 20 .

\section{Authors Profile}

Manoj Prasad Kushwaha, Pediatrician, Lumbini Zonal Hospital, Butwal, Rupandehi, Nepal (Email ID: kushwahamanoj6399[at]gmail.com). 